\title{
Pengaruh Bentuk Pola Persebaran Permukiman Penduduk terhadap RTH di Kampung Tua Tanjung Riau
}

\author{
Carissa Dinar Aguspriyanti ${ }^{1}$, Billy Shevriyanto ${ }^{2}$, Charlie $^{3}$ \\ 1,2,3 Jurusan Arsitektur, Fakultas Teknik Sipil dan Perencanaan, Universitas Internasional Batam \\ Email: ${ }^{1}$ carissa@uib.ac.id, ${ }^{2}$ 1912024.billy@uib.edu, ${ }^{3}$ 1912031.charlie@ @ib.edu
}

\begin{abstract}
The undirected distribution pattern of settlements tends to cause irregular building arrangement patterns. Coupled with the increasing building density level, the availability of open space is at risk of decreasing. The coastal settlement of Kampung Tua Tanjung Riau in Batam is a vivid example of this kind of settlements development issue. Through descriptive-qualitative research methods, the form of distribution pattern of settlements was observed from the street layout and buildings location. Subsequently, it can be identified and analysed that the longitudinal distribution pattern of settlements in Kampung Tua Tanjung Riau affects the availability of green open space in the area which is considered inadequate. This research is expected to be taken into consideration by related agencies including the government in overcoming the existing problems in Kampung Tua Tanjung Riau.
\end{abstract}

Keywords: Distribution Pattern of Settlements, Green Open Space, Kampung Tua Tanjung Riau

\begin{abstract}
Abstrak. Bentuk pola persebaran permukiman penduduk yang tidak terarah cenderung menyebabkan ketidakteraturan pola penataan bangunan. Ditambah dengan tingkat kepadatan yang semakin meningkat, ketersediaan ruang terbuka beresiko menurun. Permukiman pesisir Kampung Tua Tanjung Riau di Kota Batam, merupakan salah satu contoh nyata permasalahan perkembangan permukiman tersebut. Melalui metode penelitian kualitatif deskriptif, bentuk pola persebaran permukiman ditinjau dari pola jalan dan lokasi hunian. Kemudian, dapat diidentifikasi dan dianalisis bahwa bentuk pola persebaran permukiman yang memanjang di Kampung Tua Tanjung Riau mempengaruhi ketersediaan RTH (Ruang Terbuka Hijau) di kawasan tersebut yang notabene dinilai masih kurang memadai. Penelitian ini diharapkan dapat menjadi bahan pertimbangan instansi terkait termasuk pemerintah dalam mengatasi permasalahan yang ada di kawasan Kampung Tua Tanjung Riau.
\end{abstract}

Kata Kunci: Pola Persebaran Permukiman, Ruang Terbuka Hijau, Kampung Tua Tanjung Riau

\section{Pendahuluan}

Sebagai salah satu wilayah di Indonesia yang diputuskan sebagai Kawasan Ekonomi Khusus (KEK), Pulau Batam memiliki pertumbuhan industri dan ekonomi yang semakin berkembang tiap tahunnya. Hal ini mendorong munculnya banyak lapangan pekerjaan yang diyakini menjadi salah satu daya tarik bagi masyarakat luar Batam untuk mencari pekerjaan bahkan menetap di kota tersebut. Kondisi ini menyebabkan peningkatan kebutuhan akan tempat tinggal sehingga wilayah permukiman pun semakin meluas (Roziqin \& Kusumawati, 2017). Kawasan permukiman merupakan bagian dari suatu lingkungan hidup yang ada di perkotaan atau pedesaan dan memiliki fungsi sebagai tempat tinggal serta tempat untuk melakukan beragam aktivitas pendukung kehidupan penghuninya (Sarman \& Wijaya, 2018).

Perluasan wilayah permukiman, khususnya di area pesisir yang notabene memiliki lahan terbatas, cenderung mendorong semakin tingginya level kepadatan bangunan di wilayah tersebut. Kepadatan bangunan suatu wilayah berbanding terbalik dengan luas area hijau yang tersedia pada wilayah tersebut, yang akhirnya beresiko menjadi faktor kekumuhan bersama dengan aspek lainnya seperti tidak terdapat keteraturan pola penataan rumah tinggal dan minimnya fasilitas dan sarana publik yang memadai (Aguspriyanti et al., 2020). Selain itu, peningkatan kepadatan permukiman di kawasan pesisir yang disebabkan oleh masyarakat pendatang maupun masyarakat asli cenderung tidak terencana dengan baik, hal ini kadangkala bahkan dapat merusak perlindungan lanskap wilayah tersebut seperti pantai alami yang sudah ada (Ruzardi et al., 2004).

Kampung Tua Tanjung Riau yang berlokasi di kawasan pesisir Sekupang, Batam, merupakan salah satu dari kawasan permukiman pesisir, dengan aktivitas utama penduduknya sebagai nelayan. Seiring dengan meningkatnya jumlah hunian maka akan menyebabkan permasalahan terhadap pola 
jalan, bentuk dan lokasi bangunan yang tidak teratur, ketidaktersediaan ruang terbuka hijau dan fasilitas publik lain yang memadai, dan sebagainya. Masalah-masalah tersebut akan dapat mempengaruhi kualitas hidup penduduknya. Mempertimbangkan urgensi untuk mengurangi resiko penurunan kualitas area permukiman di Kampung Tua Tanjung Riau, penelitian ini bertujuan untuk mengetahui pengaruh pola persebaran permukiman terhadap ketersediaan RTH melalui identifikasi bentuk pola persebaran permukiman penduduk setempat. Hasil temuan penelitian ini diharapkan dapat digunakan oleh pemerintah setempat sebagai dasar kebijakan untuk mengembangkan wilayah Kampung Tua Tanjung Riau di kemudian hari.

\section{Tinjauan Pustaka}

\subsection{Permukiman Pesisir}

Hadi Sabari Yunus (1987) berpendapat bahwa permukiman merupakan tempat bertempat tinggal baik sementara maupun menetap dalam rangka menyelenggarakan kehidupannya yang dibuat oleh manusia ataupun terbentuk secara alami. Ia juga menambahkan bahwa, idealnya, permukiman dilengkapi dengan segala fasilitas pendukung yang dapat dimanfaatkan baik secara individu maupun berkelompok untuk beraktivitas didalamnya. Sedangkan, area pertemuan antara daratan dengan laut secara ekologis disebut sebagai wilayah pesisir (Julkrismi, 2018). Dengan demikian, permukiman pesisir dapat diartikan sebagai wilayah yang dibentuk sebagai tempat tinggal di perbatasan darat dan laut yang ditunjang oleh beberapa fasilitas untuk penduduk melakukan aktivitas yang umumnya berkaitan dengan profesi sebagian besar penduduk sebagai nelayan.

\subsection{Pola Persebaran Permukiman}

Terdapat faktor-faktor yang dapat mempengaruhi pola persebaran suatu permukiman, seperti kondisi topografi, aksesibilitas, penggunaan lahan, kondisi sosial dan ekonomi, serta fasilitas pendukung yang ada di dalam permukiman tersebut. Perkembangan yang terjadi pada indikator tersebut akan sangat mempengaruhi pola maupun persebaran permukiman itu sendiri. Pada dasarnya, pola permukiman dapat menunjukkan wilayah bermukim manusia dan di mana mereka dapat melakukan aktivitas sehari-hari.

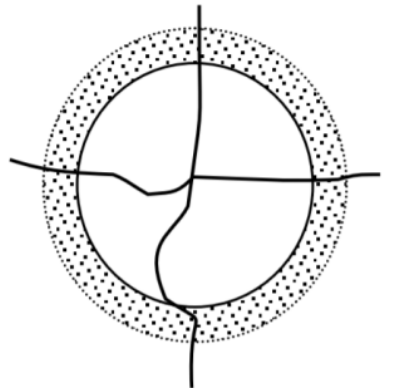

Konsentrik

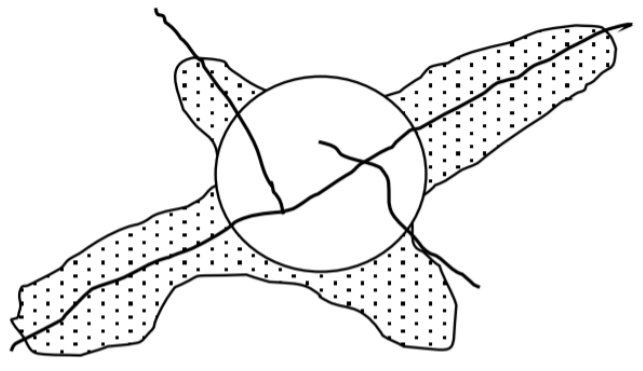

Memanjang

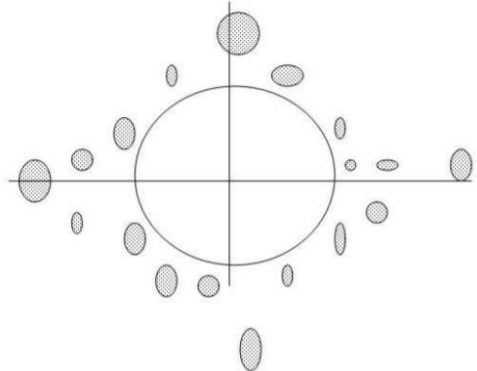

Lompatan Katak

Gambar 1. Pola Perkembangan Fisik Kota (Rifai Mardin, 2011)

Perkembangan permukiman pada umumnya membentuk suatu pola (Roziqin \& Kusumawati, 2017). Pola dan selebaran memiliki arti dan makna yang sangat erat. Mengikuti perkembangan fisik kota, perkembangan permukiman dapat dibedakan menjadi tiga bentuk pola yang dapat dilihat pada Gambar 1, yaitu (1) pola perkembangan konsentrik - pola ini terbentuk merata ke seluruh wilayah bagian luar kota yang ada sehingga cenderung membentuk suatu kenampakan pola yang relatif kompak. Pengaruh jalur transportasi pada pola perkembangan ini tidak terlalu signifikan. (2) pola perkembangan memanjang - pola ini terbentuk tidak merata di semua wilayah sisi-sisi luar pusat kota. Berkebalikan dari pola perkembangan konsentrik, tipe perkembangan ini justru terjadi cepat khususnya pada daerah yang berdekatan dengan jalur transportasi. (3) pola perkembangan lompatan katak - pola ini dinilai paling tidak efisien, cenderung merugikan dari sisi ekonomi, dan juga kurang memiliki unsur keindahan karena pola ini terbentuk sporadis (berpencar) dan biasanya berkembang di tengah-tengah suatu lahan (Rifai Mardin, 2011). Namun, jika dilihat dari sisi lain, bentuk pola seperti ini dapat memberikan kesempatan bagi ruang-ruang terbuka untuk berkembang menjadi ruang terbuka hijau yang optimal. 


\subsection{RTH (Ruang Terbuka Hijau)}

Berdasarkan standar yang diatur pada UU No. 26 Tahun 2007 tentang Penataan Ruang, jalur dan/atau mengelompok sebagai tempat tumbuh tanaman yang berupa area terbuka dapat dikatakan sebagai Ruang Terbuka Hijau. Dalam aturan tersebut juga disampaikan bahwa tanaman-tanaman yang dimaksud merupakan tanaman yang tumbuh secara alami maupun yang sengaja ditanam dan areanya dapat bersifat publik atau privat. Taman kota, taman pemakaman umum (TPU), dan jalur hijau yang berada di sepanjang jalan, sungai, dan pantai adalah contoh-contoh dari ruang terbuka hijau publik. Sedangkan, ruang terbuka hijau privat dapat berupa kebun, halaman rumah atau bangunan (baik yang dimiliki masyarakat atau swasta) yang ditanami dengan vegetasi.

Undang-undang tersebut juga mengamanatkan bahwa sudah seharusnya jumlah RTH yang tersedia mencapai $30 \%$ dari luas wilayah perkotaan. Hal ini untuk menjamin keberlangsungan ekosistem kota (sistem hidrologi, sistem iklim mikro, maupun sistem ekologis lain) yang seimbang. Selanjutnya, ketersediaan RTH akan dapat berkontribusi dalam meningkatkan ketersediaan udara bersih yang diperlukan masyarakat sembari menambah nilai estetika kota (Undang-Undang Nomor 26 Tahun 2007, 2007). Selain itu, ruang terbuka hijau kota adalah komponen terpenting yang ikut mempengaruhi kualitas hidup setiap orang, mulai dari sisi ekologis maupun sosio-psikologis (Rahmy et al., 2012). Hal ini menunjukan bahwa keberadaan RTH di wilayah perkotaan dinilai signifikan terhadap kualitas hidup masyarakat setempat. Oleh karena itu, di dalam setiap proses pengembangan suatu wilayah sudah seharusnya mempertimbangkan ketersediaan ruang terbuka hijau di wilayah tersebut.

\section{Metode Penelitian}

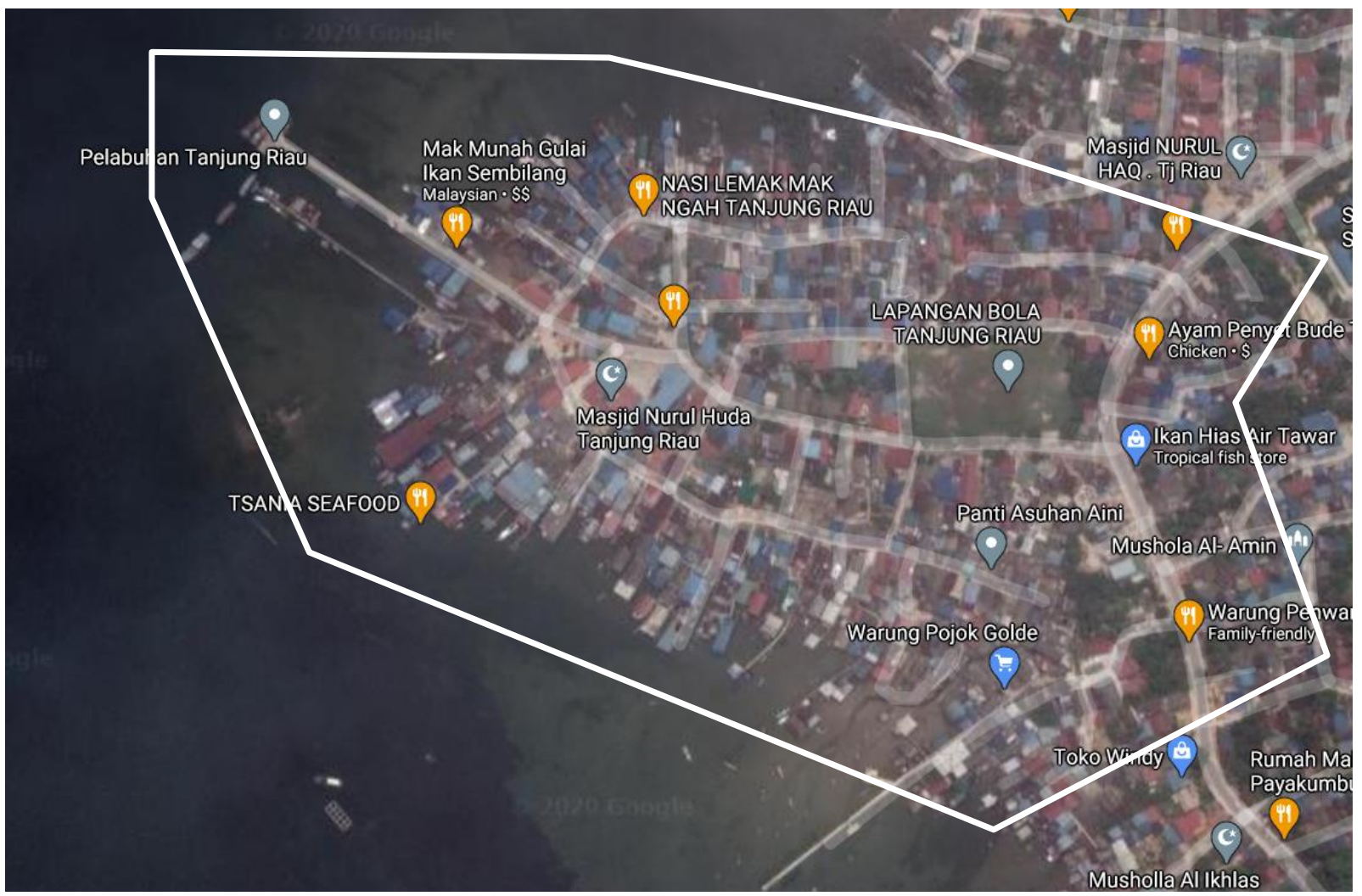

Gambar 2. Lokasi Kampung Tua Tanjung Riau

Untuk memperoleh hasil penelitian, digunakan metode kualitatif dengan pendekatan deskriptif. Berdasar pada riset yang dilakukan oleh Creswell (2015), pendekatan deskriptif adalah suatu fenomena atau kenyataan sosial yang dieksplorasi dan klarifikasi dengan maksud menjelaskan sejumlah variabel 
yang berhubungan dengan masalah dan objek yang diteliti. Pendekatan deskirptif sendiri juga disebut dengan penelitian taksonomik (taxonomic research).

Lokasi penelitian berada di Kampung Tua Tanjung Riau, Sekupang, Batam. Data bentuk pola sebaran diperoleh melalui metode interpretasi visual, yaitu dengan melakukan pengamatan terhadap persebaran permukiman penduduk di Kampung Tua Tanjung Riau melalui citra peta yang ada di internet (google earth), serta observasi secara langsung ke lokasi penelitian untuk mencocokan kesesuaian data. Bentuk pola persebaran permukiman yang diobservasi yakni seperti pola konsentris (memusat), pola memanjang (mengikuti jaringan jalan atau sungai) atau pola lompatan katak (menyebar dan tidak mengikuti pola tertentu) ditinjau dari pola jalan dan lokasi rumah tinggal.

Setelah melakukan identifikasi bentuk pola persebaran permukiman penduduk di Kampung Tua Tanjung Riau, penelitian dilanjutkan dengan menganalisis secara deskriptif pengaruh bentuk pola tersebut terhadap kondisi ruang terbuka hijau (RTH) yang ada di sana untuk dapat menarik kesimpulan dari penelitian ini.

\section{Hasil Analisis dan Pembahasan}

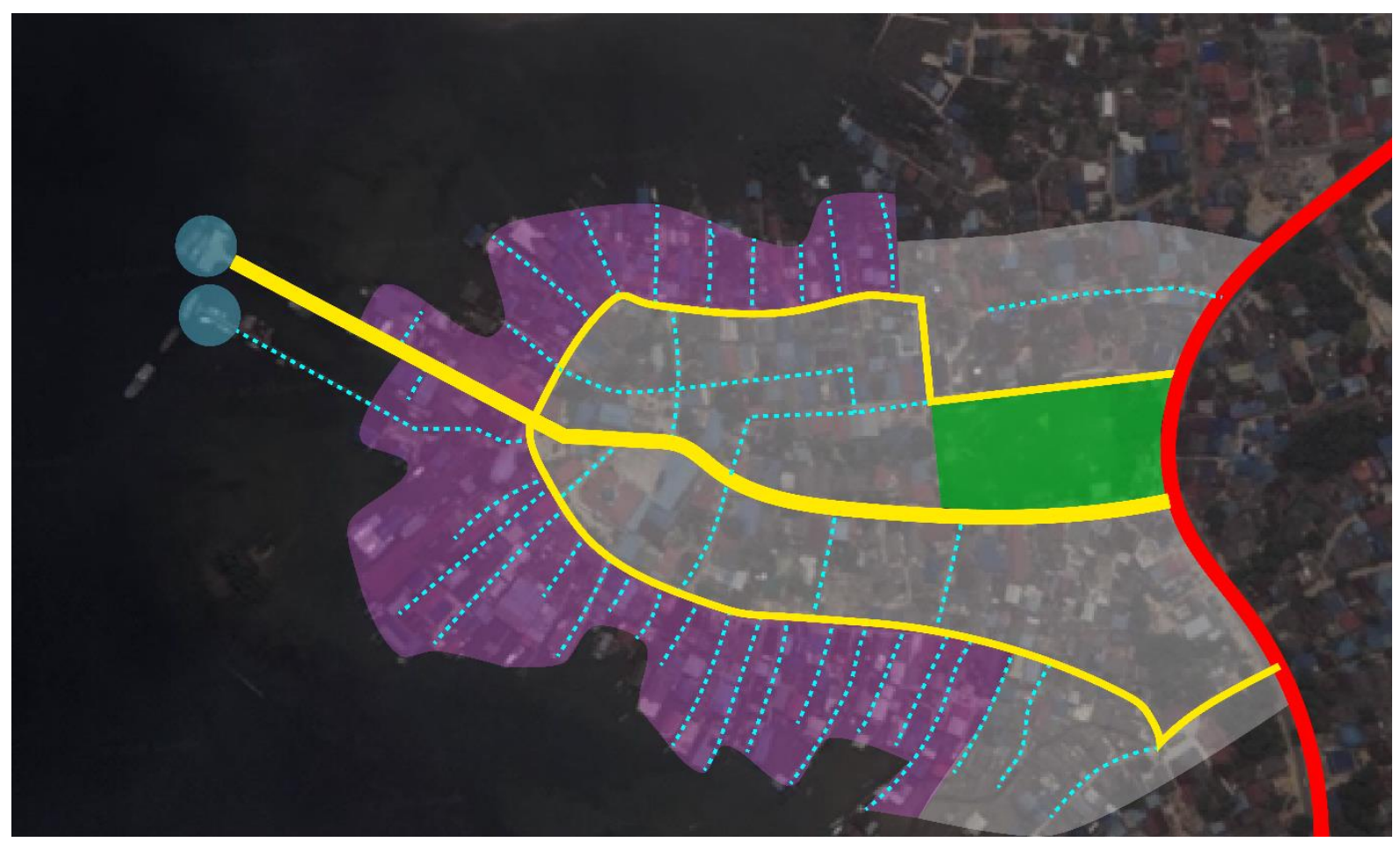

\section{Keterangan:}

- Jalan arteri kota

- Jalan primer permukiman

- - Jalan sekunder permukiman

Zona permukiman di perairan/ perbatasan darat dan perairan

Zona permukiman di darat

Ruang terbuka hijau

Dermaga/pelabuhan

\section{Gambar 3. Bentuk Pola Persebaran Permukiman Penduduk dan Sebaran Ruang Terbuka Hijau di Kampung Tua Tanjung Riau}

Berdasarkan hasil observasi dan interpretasi visual melalui citra Google Earth, dapat diidentifikasi bahwa bentuk pola persebaran permukiman penduduk di Kampung Tua Tanjung Riau cenderung menyebar secara memanjang mengikuti arah laut. Hal ini dapat ditinjau dari pola jalan yang ada dan lokasi hunian-hunian di kawasan permukiman pesisir tersebut (Gambar 3). Sejalan dengan 
kajian pustaka yang telah dilakukan, fenomena bentuk pola persebaran permukiman yang memanjang ini menunjukkan pengaruh kebutuhan penduduk setempat akan akses transportasi terhadap wilayah perairan. Mayoritas penduduk setempat berprofesi sebagai nelayan sehingga memiliki aktivitas utama di wilayah perairan.

Pada Gambar 3, dapat dilihat bahwa garis merah merupakan jalan arteri kota. Jalan primer yang berwarna kuning menunjukkan akses dari jalan arteri kota menuju wilayah perairan, khususnya menuju dermaga atau pelabuhan di Kampung Tua Tanjung Riau. Kemudian permukiman semakin berkembang dengan bertambahnya hunian yang menyebar memanjang baik di daerah daratan, perbatasan daratan dan perairan, serta perairan. Permukiman menyebar secara menjalar memenuhi bagian dari bibir pantai, seiring dengan penduduk yang membuat jalan sekunder berwarna biru yang memberikan akses terhadap jalan primer.

Berbagai zonasi permukiman pesisir Kampung Tua Tanjung Riau berdasarkan orientasi rumah juga ditunjukkan pada Gambar 3. Wilayah berwarna ungu merupakan permukiman penduduk di wilayah perbatasan daratan dan perairan atau perairan, yang menyebar secara memanjang cenderung ke arah Utara-Selatan. Sedangkan, wilayah yang berwarna abu-abu menunjukkan permukiman yang memanjang cenderung lurus ke arah Barat-Timur.

Selanjutnya, berdasarkan perhitungan dengan luas total wilayah 436,700 $\mathrm{m}^{2}$ (Humas Batam, 2013), Kampung Tua Tanjung Riau memerlukan minimal 131,010 $\mathrm{m}^{2}$ wilayah RTH pada area permukiman (jika mengacu pada aturan minimal 30\% RTH) dan hal ini tidak terpenuhi. Gambar 3 dan 4 menunjukan keberadaan lapangan hijau yang memiliki luas sekitar $6.549 \mathrm{~m}^{2}$ merupakan satu-satunya area RTH yang dapat diakses publik di Kampung Tua Tanjung Riau. Pola permukiman yang terus menerus memadat dan memenuhi wilayah Kampung Tua Tanjung Riau menyebabkan semakin berkurangnya ruang terbuka dan juga muka bibir pantai di area Kampung Tua Tanjung Riau yang sebenarnya dapat dimanfaatkan sebagai ruang terbuka hijau.

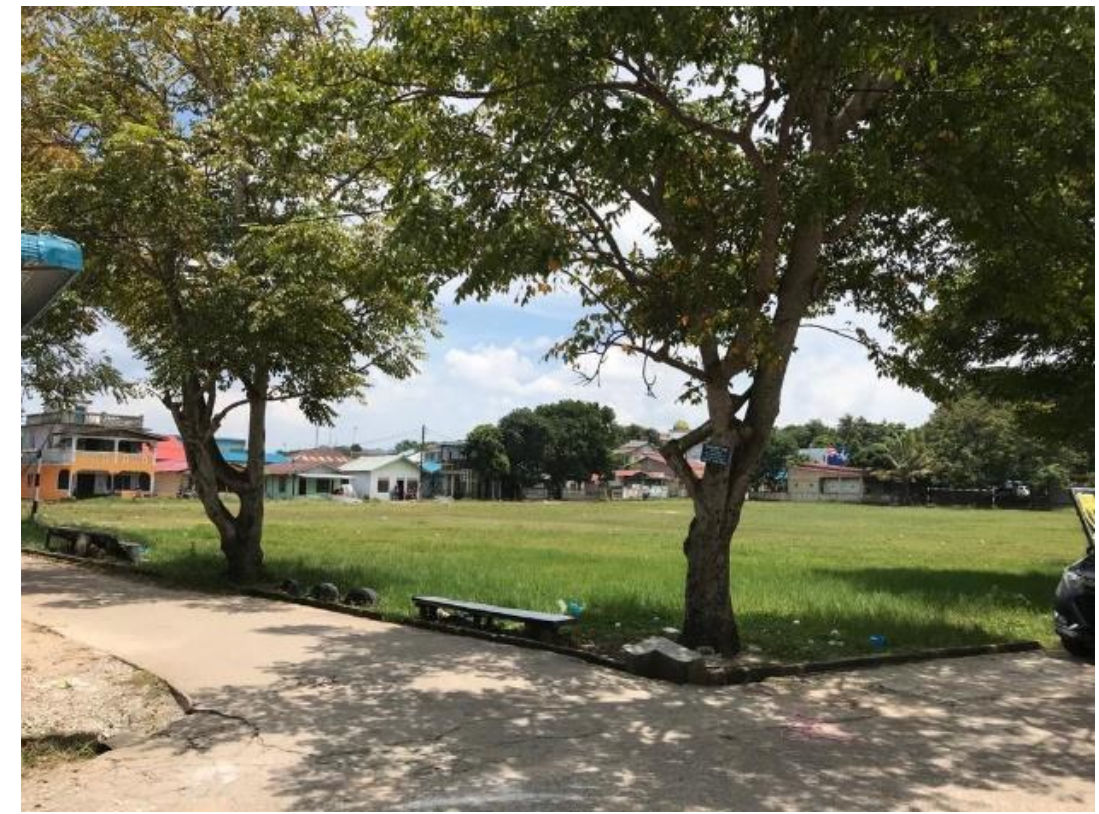

Gambar 4. Ruang Terbuka Hijau Publik di Kampung Tua Tanjung Riau

\section{Kesimpulan}

Dari uraian hasil analisis dan pembahasan, dapat disimpulkan bahwa bentuk pola persebaran permukiman penduduk di Kampung Tua Tanjung Riau adalah pola memanjang mengikuti arah laut. Pola ini dapat diidentifikasi dari kenampakan fisik pola jalan dan lokasi rumah tinggal yang ada di kawasan permukiman pesisir tersebut. Bentuk pola tersebut cenderung terbentuk karena pengaruh dari jalur transportasi atau kebutuhan akses masyarakat pesisir terhadap wilayah perairan. 
Pola persebaran permukiman penduduk merupakan hal yang cukup sulit untuk diarahkan karena menyangkut banyak pemikiran dan ego tiap masyarakat, hal ini kerap kali menyebabkan persebaran rumah tinggal yang tidak teratur. Pada kasus Kampung Tua Tanjung Riau, bentuk pola persebaran permukiman memanjang ditambah dengan semakin meningkatnya kepadatan bangunan berpengaruh pada ketersediaan RTH di kawasan tersebut.

Minimnya area RTH pada Kampung Tua Tanjung Riau akibat persebaran permukiman yang massive hingga ke bibir pantai secara berhimpitan, membuat kualitas hidup masyarakat Kampung Tua Tanjung Riau menurun. Guna memperbaiki kualitas hidup masyarakat dan juga wilayah permukiman yang minim akan RTH, maka diperlukan adanya tindak lanjut dari pihak-pihak terkait termasuk pemerintah setempat untuk memperbaiki kembali dan memperluas area RTH publik pada Kampung Tua Tanjung Riau, serta mengatur pola persebaran permukiman di area tersebut yang sudah mulai memakan area pantai. Di sisi lain, diperlukan penelitian lanjutan terhadap penyediaan ruang terbuka hijau publik di kawasan permukiman pesisir Kampung Tua Tanjung Riau untuk memperdalam solusi atas permasalahan yang ditemukan.

\section{Referensi}

Aguspriyanti, C. D., Nimita, F., \& Deviana. (2020). Analisis Faktor-Faktor Penyebab Kekumuhan di Permukiman Pesisir Kampung Tua Tanjung Riau. Journal of Architectural Design and Development, 01(02), 176-186. https://doi.org/10.37253/jad.v1i2.1501

Creswell, J. W. (2015). Penelitian Kualitatif dan Desain Riset Memilih Di Antara Lima Pendekatan (3rd ed.). Pustaka Pelajar.

Humas Batam. (2013). Masyarakat Tanjung Riau Gelar Syukuran dan Launching Kampung Tua. https://mediacenter.batam.go.id/arsip/humas/index.html\%3Fp=22507.html

Julkrismi, E. (2018). Pengaruh Pola Kehidupan Masyarakat Pesisir Terhadap Pola Pemukiman Dipantai Pasar Bawah. Proceeding of The URECOL.

Rahmy, W. A., Faisal, B., \& Soeriaatmadja, A. R. (2012). Kebutuhan Ruang Terbuka Hijau Kota pada Kawasan Padat, Studi Kasus di Wilayah Tegallega, Bandung. Lingkungan Binaan Indonesia, 1(1), 27-38.

Rifai Mardin. (2011). ANALISIS PERKEMBANGAN FISIK KOTA PALU DENGAN CITRA LANDSAT. Ruang.

Roziqin, A., \& Kusumawati, I. (2017). Analisis Pola Permukiman Menggunakan Data Penginderaan Jauh di Pulau Batam. IRONS: 8th Industrial Research Workshop and National Seminar Politeknik Negeri Bandung.

Ruzardi, R., Tamun, S., \& Rochman, B. (2004). Persepsi Pemukim di Kawasan Pantai terhadap Kerusakan Pantai (Studi Kasus Pulau Batam). Logika. https://doi.org/10.20885/logika.vol1.iss2.art7

Sarman, S., \& Wijaya, K. (2018). POLA PERMUKIMAN PESISIR PANTAI Studi Kasus: Desa Talaga 1 dan Desa Talaga 2 Kecamatan Talaga Raya Kabupaten Buton Tengah. Jurnal Arsitektur ZONASI. https://doi.org/10.17509/jaz.v1i1.11637

Undang-Undang Nomor 26 Tahun 2007. (2007). Penataan Ruang. LEMBARAN NEGARA REPUBLIK INDONESIA TAHUN 2007 NOMOR 68.

Yunus, H. S. (1987). Geografi Permukiman dan Beberapa Permasalahan Permukiman di Indonesia. Fakultas Geografi, Universitas Gadjah Mada. 